\title{
Uji kekuatan transversal resin akrilik polimerisasi panas yang direndam dalam larutan cuka aren
}

\author{
${ }^{1}$ Learny T. M. Sormin \\ ${ }^{2}$ Jimmy F. Rumampuk \\ ${ }^{3}$ Vonny N. S. Wowor \\ ${ }^{1}$ Kandidat skripsi Program Studi Pendidikan Dokter Gigi Fakultas Kedokteran \\ ${ }^{2}$ Bagian Fisika Fakultas Kedokteran \\ ${ }^{3}$ Program Studi Pendidikan Dokter Gigi Fakultas Kedokteran \\ Universitas Sam Ratulangi Manado \\ Email: merilyn.sormin@yahoo.com
}

\begin{abstract}
Acrylic resin is a material used for denture base frequently used in field dentistry. One characteristic of an acrylic resin is its strength against pressure. Strength is needed in a denture withstand the force from chewing received by the denture. The strength of a denture base material can be affected by the user's habit of eating acidic food and beverages. Palm vinegar is an acidic kitchen ingredient obtained from the fermentation of palm sap and is usually used in North Sulawesi's snack called gohu which is widely consumed by the population. This study was aimed to determine the transverse strength of an acrylic resin plate after being soaked in a palm vinegar solution. This was a laboratory study with a posttest control group design. There were 24 samples distributed in one control group and three treament groups. The samples were immersed for 5 and 10 days in the palm vinegar solution. The transverse test used a Universal Testing Machine. The results showed that after 5 days, the average transverse strength of acrylic resin plate was $94 \mathrm{~N} / \mathrm{mm}^{2}$ in the less acidic palm vinegar solution; $88.3 \mathrm{~N} / \mathrm{mm}^{2}$ in the acidic solution; and $80 \mathrm{~N} / \mathrm{mm}^{2}$ in the highly acidic solution. After 10 days the average transverse of acrylic resin plate was $89.3 \mathrm{~N} / \mathrm{mm}^{2}$ in the less acidic palm vinegar solution; $87.7 \mathrm{~N} / \mathrm{mm}^{2}$ in the acidic solution, $46,3 \mathrm{~N} / \mathrm{mm}^{2}$ in the high acidic solution. Conclusion: The higher the concentration levels of palm vinegar in the solution, the lower the transverse strength of acrylic resin.
\end{abstract}

Keywords: acrylic resin, palm vinegar solution, transverse strength

\begin{abstract}
Abstrak: Resin akrilik merupakan bahan basis gigi tiruan yang sudah sering dipakai di bidang kedokteran gigi. Salah satu sifat resin akrilik ialah kuat terhadap tekanan. Kekuatan basis dibutuhkan antara lain untuk menahan kekuatan daya kunyah yang diterima oleh gigi tiruan. Kekuatan bahan basis gigi tiruan dapat dipengaruhi oleh kebiasaan pengguna gigi tiruan dalam mengonsumsi makanan dan minuman bersifat asam. Cuka aren ialah salah satu bahan dapur yang bersifat asam yang didapat dari hasil fermentasi nira aren dan biasanya dipakai dalam jajanan tradisional khas Sulawesi Utara yakni gohu. Jajanan tersebut banyak dikonsumsi oleh masyarakat Sulawesi Utara. Penelitian ini bertujuan untuk mengetahui kekuatan transversal plat resin akrilik setelah direndam dalam larutan cuka aren. Jenis penelitian ialah laboratorik dengan post-test control group design. Sampel penelitian sebanyak 24 buah plat resin akrilik yang didistribusikan dalam 1 kelompok kontrol dan 3 kelompok perlakuan. Perendaman plat tersebut dilakukan selama 5 dan 10 hari. Uji kekuatan transversal dilakukan menggunakan alat Universal Testing Machine. Hasil penelitian mendapatkan setelah 5 hari perendaman dalam larutan cuka aren kurang asam rerata kekuatan transversal plat resin akrilik sebesar $94 \mathrm{~N} / \mathrm{mm}^{2}$; sebesar $88,3 \mathrm{~N} / \mathrm{mm}^{2}$ dalam larutan asam; dan sebesar $80 \mathrm{~N} / \mathrm{mm}^{2}$ dalam larutan sangat asam. Setelah 10 hari perendaman dalam
\end{abstract}


larutan cuka aren kurang asam rerata kekuatan transversal plat resin akrilik sebesar 89,3 $\mathrm{N} / \mathrm{mm}^{2}$ sebesar $87,7 \mathrm{~N} / \mathrm{mm}^{2}$ dalam larutan asam dan sebesar $46,3 \mathrm{~N} / \mathrm{mm}^{2}$ dalam larutan sangat asam. Simpulan: Semakin tinggi kadar konsentrasi keasaman larutan cuka aren, semakin rendah kekuatan transversal resin akrilik.

Kata kunci: resin akrilik, larutan cuka aren, kekuatan transversal

Resin akrilik merupakan bahan material yang sudah sering dipakai di bidang kedokteran gigi. Resin akrilik dipakai karena bahan ini memiliki kelebihan estetika yang baik, tekstur mirip gingiva, mempunyai daya serap air yang relatif rendah, dan perubahan dimensi yang kecil. Sejak pertengahan tahun 1940-an, resin akrilik terutama polimetil-metakrilat (PMMA) sangat sering digunakan sebagai bahan basis gigi tiruan di bidang kedokteran gigi. ${ }^{1,2}$

Basis gigi tiruan merupakan tempat melekatnya elemen gigi tiruan. Bahan basis gig tiruan mempunyai beberapa syarat antara lain kuat terhadap tekanan dan penampilan estetika yang baik. Kekuatan basis dibutuhkan antara lain untuk menahan kekuatan daya kunyah yang diterima oleh gigi tiruan., ${ }^{3,4}$ Tidak jarang terjadi gigi tiruan yang digunakan patah atau retak saat dipakai mengunyah. Terdapat beberapa faktor yang memengaruhi kekuatan basis gigi tiruan, yaitu bahan yang digunakan untuk membuat gigi tiruan, manipulasi bahan, dan suasana $\mathrm{pH}$ dalam mulut yang dipengaruhi oleh makanan dan minuman yang dikonsumsi. ${ }^{5}$ Penelitian oleh Rini menyimpulkan bahwa perendaman resin akrilik dalam kopi ulee kareng yang bersifat asam dapat memengaruhi kekerasan dari resin akrilik dan juga berdampak pada kekuatan transversalnya. ${ }^{6}$

Kebiasaan masyarakat mengonsumsi makanan dan minuman yang asam terbentuk dari pola hidup masyarakat. Berbagai jenis makanan atau minuman yang dikonsumsi telah menjadi ciri khas atau karateristik yang identik dengan masyarakat daerah tertentu. Sulawesi Utara merupakan salah satu provinsi dengan kondisi geografis yang terdiri dari daerah pantai dan pegunungan. Banyaknya masyarakat yang tinggal di daerah pegunungan yang bercuaca dingin, menyebabkan mereka lebih sering mengonsumsi minuman yang berasal dari nira aren, masyarakat Sulawesi Utara mengenalnya sebagai minuman saguer. Sisa dari minuman saguer inilah yang difermentasi masyarakat Sulawesi Utara dengan cara dibiarkan dan berlangsung terus, akan berubah menjadi asam cuka yang dikenal oleh masyarakat sebagai cuka aren.

Cuka aren banyak digunakan masyarakat Sulawesi Utara untuk campuran sejenis makanan khas yaitu gohu yang terbuat dari buah pepaya setengah matang. Masyarakat lebih suka mencampurkan cuka yang berasal dari hasil fermentasi nira aren, dikarenakan cuka yang berasal dari nira aren memiliki aroma khas dan rasanya lebih enak daripada cuka yang ada di pasaran. Beberapa literatur mengatakan bahwa salah satu akibat dari mengonsumsi minuman yang mengandung asam akan menimbulkan kerusakan pada gigi tiruan resin akrilik. ${ }^{7}$ Asam dari minuman atau makanan yang dikonsumsi akan berpengaruh pada kekuatan tranversal basis gigi tiruan resin akrilik.

Kekuatan transversal merupakan ketahanan basis resin akrilik terhadap beban, tekanan, dan gaya dorong sewaktu mulut berfungsi. Akibat pengaruh asam, maka kemampuan basis gigi tiruan resin akrilik untuk menahan beban menjadi berkurang. Melalui uji kekuatan transversal dapat diperoleh gambaran tentang ketahanan basis gigi tiruan dalam menerima beban pada waktu pengunyahan. ${ }^{8}$

Penelitian ini bertujuan untuk mengetahui kekuatan transversal resin akrilik polimerisasi panas yang direndam dalam larutan cuka aren yang terbagi dalam konsentrasi kurang asam, asam, dan sangat asam. 


\section{BAHAN DAN METODE PENELITIAN}

Jenis penelitian ini ialah eksperimental laboratoris dengan post-test only group design. Alat yang digunakan dalam penelitian terdiri dari: rubber bowl, spatula, kuvet, mixing jar, kompor, panci, botol kaca $100 \mathrm{ml}$, pinset, lecron, kertas lakmus, gelas ukur, timbangan digital, penggaris, pensil, kertas pasir, gunting, pulpen, dan Universal Testing Machine. Bahan yang digunakan dalam penelitian terdiri dari: gips putih, malam merah, powder dan liquid resin akrilik polimerisasi panas merk QC 20, cold mold space (CMS), vaseline, cuka aren, dan aquades steril.

Sampel yang digunakan ialah 24 buah plat akrilik utuh dengan ukuran $65 \times 10 \mathrm{x}$ 2,5 mm. Cuka aren yang dipakai dalam penelitian berasal dari hasil fermentasi nira aren yang didapat dari Desa Kalawiran Kecamatan Kombi Kabupaten Minahasa. Cuka aren ini dilarutkan dalam akuades steril dan dibagi dalam beberapa konsentrasi yaitu kurang asam, asam dan sangat asam. Larutan cuka aren ini mewakili selera orang dalam memilih tingkat rasa asam pada makanan atau minuman yang dikonsumsi.

Perendaman sampel dilakukan selama 5 dan 10 hari. Dua belas sampel plat resin akrilik pertama direndam selama 5 hari dalam konsentrasi kurang asam, asam, sangat asam, dan kelompok kontrol; masing-masing kelompok mendapat 3 sampel plat resin akrilik. Dua belas sampel plat resin akrilik kedua yang direndam selama 10 hari dalam konsentrasi kurang asam, asam, dan kelompok kontrol; masing-masing kelompok mendapat 3 sampel plat resin akrilik. Pengujian kekuatan transversal menggunakan alat Universal Testing Machine di Laboratorium Rekayasa Material Teknik Sipil Fakultas Teknik Universitas Sam Ratulangi.

\section{HASIL PENELITIAN}

Hasil pada Tabel 1 dan Tabel 2 menunjukkan rerata hasil uji kekuatan transversal plat resin akrilik yang direndam dalam larutan cuka saguer selama 5 hari dan 10 hari dengan konsentrasi yang berbeda-beda. Terjadi penurunan kekuatan transversal plat resin akrilik yang direndam selama 10 hari dalam larutan cuka aren pada konsentrasi sangat asam

Tabel 1. Rerata hasil uji kekuatan tranversal plat resin akrilik $\left(\mathrm{N} / \mathrm{mm}^{2}\right)$ selama perendaman 5 hari

\begin{tabular}{|c|c|c|c|c|}
\hline \multirow[t]{2}{*}{ Sampel } & \multicolumn{4}{|c|}{$\begin{array}{c}\text { Kekuatan transversal plat resin } \\
\text { akrilik }\left(\mathrm{N} / \mathrm{mm}^{2}\right)\end{array}$} \\
\hline & $\begin{array}{c}\text { Kurang } \\
\text { asam }\end{array}$ & Asam & $\begin{array}{l}\text { Sangat } \\
\text { asam }\end{array}$ & Kontrol \\
\hline 1 & 114 & 74 & 99 & 71 \\
\hline 2 & 110 & 86 & 72 & 106 \\
\hline 3 & 58 & 105 & 69 & 36 \\
\hline Rerata & 94 & 88,3 & 80 & 71 \\
\hline
\end{tabular}

Tabel 2. Rerata hasil uji kekuatan transversal plat resin akrilik $\left(\mathrm{N} / \mathrm{mm}^{2}\right)$ selama perendaman 10 hari

\begin{tabular}{ccccc}
\hline \multirow{2}{*}{ Sampel } & \multicolumn{4}{c}{$\begin{array}{c}\text { Kekuatan transversal plat resin } \\
\text { akrilik (N/mm }\end{array}$} \\
\cline { 2 - 5 } & $\begin{array}{c}\text { Kurang } \\
\text { asam }\end{array}$ & Asam & $\begin{array}{c}\text { Sangat } \\
\text { asam }\end{array}$ & Kontrol \\
\hline 1 & 50 & 46 & 59 & 86 \\
2 & 149 & 141 & 27 & 116 \\
3 & 69 & 76 & 53 & 74 \\
Rerata & 89,3 & 87,7 & 46,3 & 92 \\
\hline
\end{tabular}

\section{BAHASAN}

Hasil penelitian yang dilakukan setelah plat resin akrilik direndam dalam larutan cuka aren dan kelompok kontrol dengan perbedaan konsentrasi dan beberapa waktu perendaman memperlihatkan hasil kekuatan transversal berbeda-beda. Perbedaan ini terjadi karena cara memanipulasi bahan yang menyebabkan adanya perbedaan ketebalan di masingmasing sampel. Pada saat memanipulasi bahan terdapat beberapa proses yang tidak diperkirakan misalnya pada proses pencetakan malam merah di kuvet yang sudah berisi gips putih terdapat kesulitan untuk mencari ketebalan yang sesuai dengan ukuran sampel yang sudah ditentukan dikarenakan malam merah tidak mempunyai ukuran tebal $2,5 \mathrm{~mm}$. Pada proses pemolesan terjadi penipisan sampel plat akrilik. Selain itu, adanya porositas 
yang tidak terlihat pada saat pembuatan atau pengadukan bubuk dan cairan resin akrilik, sehingga kekuatan transversal yang didapatkan oleh setiap plat akrilik jauh berbeda-beda. Selain tergantung pada cara manipulasi bahan, komposisi bahan, serta porositas yang tidak terlihat saat proses pembuatan hingga proses curing. Kekuatan transversal dipengaruhi juga dengan kandungan monomer sisa yang masih tertinggal.

Kandungan monomer sisa yang tinggi dapat memengaruhi sifat fisik polimer yang dihasilkan karena monomer sisa akan bertindak sebagai plasticizer dan membuat resin akrilik menjadi fleksibel dan kekuatan menurun. Bukan hanya itu, kandungan monomer sisa yang tinggi berpotensi untuk menyebabkan iritasi jaringan mulut, inflamasi, dan alergi terutama daerah mukosa di bawah gigi tiruan. ${ }^{9}$

Resin akrilik polimerisasi panas mempunyai sifat fisik salah satunya yaitu mampu menyerap air. Kemampuan menyerap air inilah yang membuat kekuatan transversal pada resin akrilik polimerisasi panas dapat berubah entah semakin kuat atau semakin rapuh. Ketahanan resin akrilik juga tergantung dengan cara seseorang mengonsumsi makanan atau minuman.

Kekuatan basis gigi tiruan yang lama terpapar larutan asam dapat mengalami penurunan kekuatan fleksural. Penurunan kekuatan tersebut menunjukkan semakin lemahnya bahan basis gigi tiruan dalam menahan gaya pengunyahan dan fraktur basis gigi tiruan. Pengaruh asam inilah yang dapat memengaruhi kekuatan pada bahan basis gigi tiruan. ${ }^{10}$

Resin akrilik yang direndam pada suatu larutan akan terpengaruh sifat fisiknya. Larutan perendam mampu berpenetrasi masuk ke dalam ruang mikroporositas resin akrilik dan mempengaruhi ikatan antar molekulnya. ${ }^{2}$ Ikatan antar molekul menurun yang dapat menurunkan kekuatan resin akrilik termasuk kekuatan transversal. Kemung-kinan lain adanya larutan asam dari larutan cuka aren bila bereaksi dengan resin akrilik akan menyebabkan perubahan kimia, yaitu yang terjadi adalah kelarutan beberapa bahan pengisi. Adanya kelebihan ion $\mathrm{H}^{+}$pada kelarutan asam akan menyebabkan ketidakstabilan ikatan kimia dari resin akrilik. Ion $\mathrm{H}^{+}$dari asam menyebabkan degradasi ikatan polimer sehingga beberapa monomer dari resin akrilik melepaskan diri, yang disertai pelepasan bahan pengisi yang ada. ${ }^{11,12}$

Resin akrilik sebagaimana polimer lainnya memiliki dua macam ikatan yaitu ikatan primer dan ikatan sekunder. Ikatan primer merupakan ikatan antar atom dalam rantai sedangkan ikatan sekunder merupakan ikatan antar rantai-rantainya. Ikatan primer resin akrilik memiliki kekuatan yang baik, namun ikatan sekundernya lemah. Ikatan sekunder yang lemah inilah yang diduga menyebabkan rendahnya ketahanan resin akrilik. Semakin lama masa perendaman maka semakin banyak pula partikel larutan yang dapat berpenetrasi ke ruang mikroporositas akrilik resin. Pengaruh yang terjadi pada ikatan ini akan membuat kekuatan mekanisnya semakin berkurang, termasuk kekuatan transversalnya. ${ }^{13}$

\section{SIMPULAN}

Berdasarkan hasil penelitian yang telah dilakukan dapat disimpulkan bahwa semakin lama perendaman plat resin akrilik polimerisasi dalam larutan cuka aren dan semakin tinggi konsetrasi keasaman larutan cuka aren maka semakin rendah kekuatan transversal resin akrilik.

\section{SARAN}

Bagi pemerintah, penelitian ini dapat menjadi informasi kepada pihak Puskesmas dalam upaya preventif dan promotif bagi pengguna gigi tiruan agar dapat menghindari pola makan dan minum yang asam.

Bagi masyarakat yang menggunakan gigi tiruan agar dapat mengurangi, dan membatasi konsumsi makanan dan minuman yang mengandung asam.

Bagi penelitian selanjutnya dapat lebih memerhatikan rancangan penelitian agar penelitian lebih terkontrol dan terarah. 


\section{DAFTAR PUSTAKA}

1. Tandon R, Gupta S, Agarwal S K. Denture base material from past to future. IJDS. 2010;2(2):33-8.

2. Anusavice K J. Phillips: Buku ajar ilmu kedokteran gigi. Jakarta: EGC, 2003; p.197-18.

3. Geovani V. Pengaruh perasan daun salam (Eugenia polyantha Wight) $80 \%$ sebagai pembersih gigi tiruan terhadap kekuatan tekan resin akrilik tipe heat cured dengan variasi lama perendaman. Jember: Universitas Jember; 2012.

4. Craig RG, Powers JM. Dental materials: Properties and Manipulation (7th ed). India: Mosby, 2000.

5. Rajenderan TAL. Pengaruh perendaman basis gigi tiruan resin akrilik polimerisasi panas dalam larutan peroksida alkali terhadap perubahan dimensi dan kekuatan transversal. Medan: Universitas Sumatera Utara; 2015.

6. Putri RD. Effect of ulee kareng Aceh coffee on the hardness of acrylic resin denture base. Dentofasial. 2011;10(3): 135-39

7. Indiani SR. The transversal strength of acrylic resin plate after being immersed soaking in Noni Fruit (Morinda citrifolia Linn.). J Dent. 2008;41(2):84.

8. Lestari WA. Pengaruh lama perendaman plat gigitiruan akrilik dalam ekstrak kelopak bunga rosella terhadap kekuatan tranversa plat akrilik gigitiruan. Makassar: Universitas Hassanudin; 2012.

9. Nirwana I. Kekuatan transversa resin akrilik hybrid setelah penambahan glass fiber dengan metode berbeda. Maj Ked Gigi (Dent J). 2005;38(1):169

10.Amalia A, Mozartha M, Trisnawaty. Pemaparan cuka pempek terhadap kekuatan fleksural basis gigi tiruan nilon termoplastik. Proceeding Integration of Sciences, clinical skills and technology to improve dental advanced. 2013; p. 98-103.

11.Billmeyer FW. Textbook of Polimer Sciences (3rd ed). New York: John Willey and Sons, 1974; p:11-16.

12.Pribadi SB, Yogiartono $M$, Agustantina TH. Perubahan kekuatan impak resin akrilik polimerisasi panas dalam perendaman larutan cuka apel. Dentofasial. 2010;9(1):13-20.

13.O'Brien JW. Dental materials and their selection (3rd ed). Chicago: Quintessence. 